\title{
Systemic Lupus Erythematosus Revealed by Severe Acute Pancreatitis: A Case Report
}

\author{
Mourad Badri", Abdelouhab EL Marouni, Ahmed Zerhouni, Tarek Souiki, Imane Toughraï, Khalid Mazaz, Karim IBN
} Majdoub Hassani

Service of Visceral and Endocrinological surgery II, CHU HASSAN II, Fes, Morocco

DOI: $10.36347 /$ sjmcr.2020.v08i03.027

| Received: 05.03.2020 | Accepted: 12.03.2020 | Published: 19.03.2020

*Corresponding author: Mourad Badri

Abstract

Case Report

Systemic lupus erythematosus (SLE) is an autoimmune inflammatory disease, characterized by multi-systemic involvement and acute pancreatitis is a rare condition associated with systemic lupus erythematosus. In this publication, we report the case a 40 years old patient, admitted to the OR in a table of severe pancreatitis that revealed a systemic lupus erythematosus, until then unknown, and which probably lead to the pancreatitis as one of his rare complications.

Keywords: severe pancreatitis, SLE.

Copyright @ 2020: This is an open-access article distributed under the terms of the Creative Commons Attribution license which permits unrestricted use, distribution, and reproduction in any medium for non-commercial use (NonCommercial, or CC-BY-NC) provided the original author and source are credited.

\section{INTRODUCTION}

The appearance of acute pancreatitis during systemic lupus erythematosus (SLE) is established but rare, and exceptionally revealing. Its pathophysiology is multifactorial and it is extremely difficult to distinguish what amounts to vasculitis, thrombotic phenomena or intercurrent complications. We report in this observation, the case of a patient admitted to the emergency room in a table of severe acute pancreatitis, in which the etiological investigations have revealed an LES so far unknown.

\section{ObServation}

A 40 years old patient, followed for rheumatic disease under NSAIDs, admitted to the emergency room with severe sepsis, and transfixing epigastric pain associated to food vomiting, evolving for 4 days.

The clinical examination found a febrile patient at $38.2^{\circ} \mathrm{c}$, with a pulse at $105 \mathrm{~b} / \mathrm{m}$, and a diffusé abdominal sensibility, more important in the epigastric region. We also noticed the presence of an erythema on the face.

Biologically: lipasemia was 62 times the normal value, anemia at $5.5 \mathrm{~g} \mathrm{/} \mathrm{dl}$ and hyperleukocytosis at $19000 / \mathrm{uL}$, thrombocytopenia at 97000 / uL, CRP at $377 \mathrm{mg} / \mathrm{L}$, serum potassium at 2.6 $\mathrm{mEq} / \mathrm{L}$, natremia at $133 \mathrm{mEq} / \mathrm{L}$, urea at $0.19 \mathrm{~g} / \mathrm{L}$, and creatinine at $6 \mathrm{mg} / \mathrm{L}$.

We requested an abdominal CT scan which diagnosed stage E pancreatitis with a severity score of 6 , and the presence of peri-pancreatic collections (thinwalled, enhanced, with no air bubbles) in the omental bursa and the inter-spleno-gastric space, and presence of a medium abundance of intraperitoneal effusion. Also noticed a bilateral pleural effusion of low abundance, better characterized on chest radiography. The ultrasound complement objectified a non-lithiasic gallbladder, with thickened wall, probably reactive. 


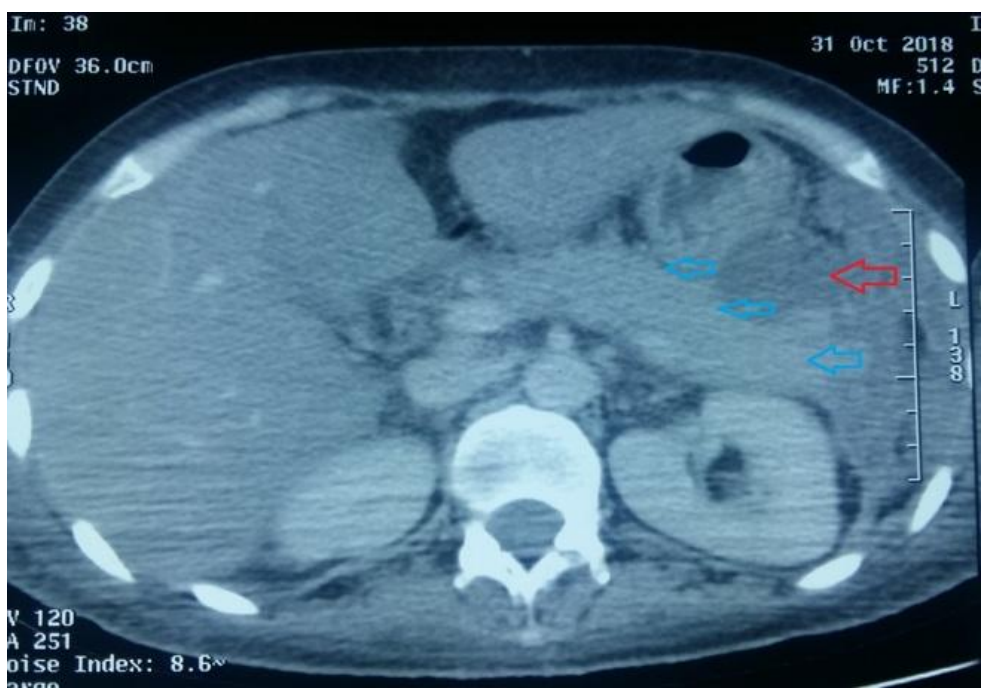

In blue: enlargement and necrosis of the pancreas. In red: collection in the omental bursa

The patient was admitted to the intensive care department where she was put on monitoring, oxygen, basic ration with hydration, analgesics, gastric protection and preventive anticoagulation.

In front of dermatological lesions of the face (erythema in butterfly wings), the concept of photosensitivity, hair loss, arthralgia of the inflammatory type and Reynaud phenomenon, an opinion from internal medicine was requested. The diagnosis of Lupus was confirmed by the presence of positive antinuclear antibodies, positive native antiDNA antibody and a low serum C3 and C4 complement level, with non-erosive polyarthritis on X-rays of the hands and feet.

The diagnosis of Pancreatitis of lupus origin was made in view of the high lipase level and in the absence of other known causes of pancreatitis; including no gallbladder stones, or drug or alcoholic intoxication, no notion of trauma, no known or discovered tumor cause on $\mathrm{CT}$, and an undisturbed metabolic balance.

In the intensive care unit, the patient underwent radiological drainage of the abdominal collections, and then was put on corticosteroid therapy after confirmation of the diagnosis of systemic lupus erythematosus. However, the patient was not given any antibiotics because the results of the bacteriological study of the samples from the drainage of the collections returned negative. The evolution was marked by the installation of cardiogenic shock with multi-visceral failure and death.

\section{DISCUSSION}

Acute lupus erythematosus is an autoimmune disease that can affect many organs, including the pancreas. Pancreatic involvement is rare, and confirming formally the responsibility for lupus in the occurrence of pancreatitis remains very difficult, even during the autopsy [1]. In the situation of our patient, the origin of acute pancreatitis remained ambiguous; an ambiguity favored by the fact that the course of acute pancreatitis during lupus is most often favorable [1]. However, forms with death have already been reported [2].

The probable pathophysiological mechanisms are in fact multiple; we can cite [3-5]:

- Ischemic phenomena such as lupus vasculitis (hypo-perfusion by vascular obliteration (arteriolite, thrombosis).

- Autoimmune mechanisms.

- A major hypertriglyceridemia is sometimes encountered in lupus (which is not the case for our patient).

- Thiazide diuretics.

- An intercurrent infectious cause (especially in patients on long-term corticosteroid therapy).

Clinically, the disease is dominated by abdominal pain, associated or not with nausea and / or vomiting [6]. Most patients with pancreatitis would present with multi-visceral manifestations; pancreatic involvement is more often acute than chronic [7]. Pancreatitis is indicative of SLE in $22 \%$ of cases and is correlated with an acute flare-up of lupus [8].

Concerning the imaging, CT images could include either a diffuse or a focal enlargement of the pancreas [9]. Finally, the evolution of pancreatitis during LSE is rarely fatal. The complications are the same as for other pancreatitis, namely pseudocysts, calcifications of the pancreas, necrosis of the pancreas, and exocrine pancreatic insufficiency [1].

In our case, the exact cause of death could not be formally specified and probably stems from multiple 
causes: acute pancreatitis, cardiogenic shock secondary to tamponade.

\section{Conclusion}

Acute severe pancreatitis can be linked to LSE especially after the exclusion of other causes. Diagnosis and early management, help reduce complications and therefore improve the prognosis.

\section{REFFERENCE}

1. Ben BD, Aydi Z, Boussema F, Ben FD, Baili L, Ketari S, Cherif O, Rokbani L. Lupus pancreatitis: a case series of six patients. La Revue de medecine interne. 2013 Jan;34(1):12-6.

2. Bruijn JA, Van Albada-Kuipers A, Smit VT, Eulderink F. Acute pancreatitis in systemic lupus. Scand J Rheumatol. 1986;15:363-7.

3. Larino Noia J, Macías García F, Seijo Ríos S, Iglesias García J, Domínguez Munoz JE. Pancreatitis and systemic lupus erythematosus. Rev Esp Enferm Dig. 2009;101:571-9.
4. Takahashi N, Kawashima A, Fletcher JG, Chari ST. Renal involvement in patients with autoimmune pancreatitis: CT and MR imaging findings. Radiology. 2007;242:791-801.

5. Lê Thi Huong Du, Papo T, Laraki R, Wechsler B, Blétry $\mathrm{O}$, Chapelon C. Pancréatite au cours du lupus érythémateux disséminé. Revue de la littérature à propos de cinq observations. Rev Med Interne. 1994;15:89-94.

6. Tian XP, Zhang X. Gastrointestinal involvement in systemic lupus erythematosus: insight into pathogenesis, diagnosis and treatment. World $\mathrm{J}$ Gastroenterol. 2010;16:2971-7.

7. Uchida K, Okazaki K, Konishi Y, Ohana M, Takakuwa H, Hajiro K. Clinical analysis of autoimmune-related pancreatitis. Am J Gastroenterol. 2000;95:2788-94.

8. Dhir V, Misra R, Agarwal V, Lawrence A, Aggarwal A. Lupus pancreatitis: early manifestation of active disease. Lupus. 2011;20:547-8.

9. Koga Y, Yamaguchi K, Sugitani A, Chijiiwa K, Tanaka M. Autoimmune pancreatitis starting as a localized form. J Gastroenterol. 2002;37:133-7. 